\title{
KULEUVEN
}

Department of Mechanical Engineering

Energy Systems Integration \& Modeling Group

Energy Systems Integration \& Modeling Group Working Paper Series

No. ESIM2020-16

\section{Capacity credit of storage in long-term planning models and capacity markets}

Tim Mertens, Kenneth Bruninx, Jan Duerinck and Erik Delarue

Last update: October 19, 2020

All working papers, including the latest version of this paper, may be downloaded from: www.mech. kuleuven.be/en/tme/research/energy-systems-integration-modeling 


\title{
Capacity credit of storage in long-term planning models and capacity markets
}

Tim Mertens, University of Leuven/VITO, EnergyVille, tim.mertens@kuleuven.be

Kenneth Bruninx, University of Leuven, EnergyVille kenneth.bruninx@kuleuven.be

Jan Duerinck, VITO, EnergyVille, jan.duerinck@vito.be

Erik Delarue, University of Leuven, EnergyVille, erik.delarue@kuleuven.be*

\begin{abstract}
Capacity credits, i.e., metrics that describe the contribution of different technologies in meeting the load during peak demand periods, are widely used in the context of long-term energy-system optimization models to ensure a predefined level of firm capacity. In the same vain, such capacity credits may be used in capacity markets to reflect the availability of an asset during periods of peak demand. For storage technologies it seems that there is a discrepancy between the capacity credit value that correctly captures the capacity contribution to the capacity target, and the capacity credit that correctly values the storage capacity. This is illustrated in a case study, which shows the differences in planning model outcomes when different capacity credit interpretations are used. Our results indicate that defining the capacity credit according to the contribution to the capacity target overvalues storage technologies, causing overinvestments. On the contrary, defining the capacity credit to reflect the value of the storage capacity, triggers the correct amount of storage investments, but underestimates the true peak reduction potential, which results in overinvestments in other firm capacity providers. In this regard, to eliminate all technology biases a novel approach is introduced that leverages both capacity credit interpretations simultaneously.
\end{abstract}

Keywords - Capacity credit; Capacity value; Storage; Long-term planning; Planning reserve margins.

*Corresponding author at: University of Leuven, Department of Mechanical Engineering, TME Branch, Celestijnenlaan 300,

3001 Heverlee (Leuven), Belgium. Tel: +32 163225 21. E-mail address: erik.delarue@kuleuven.be 


\section{Nomenclature}

\section{Abbreviations}

CC Capacity credit

CC PLR Peak load reduction-based capacity credit

$\mathrm{CC}^{\mathrm{SV}} \quad$ Scarcity value-based capacity credit

CSP Concentrated solar power

EC Energy capacity

ECP Equivalent conventional power

EFC Equivalent firm capacity

ELCC Effective load carrying capability

ENS Energy not served

EP Energy to power ratio

IRES Intermittent renewable energy sources

LOLP Loss of load probability

MREC Minimally required energy capacity

PDRC Peak demand reduction credit

PHS Pumped hydro storage

PRM Planning reserve margin

RLDC Residual load duration curve

TES Thermal energy storage

TSR Total scarcity rents

VOLL Value of lost load

\section{Sets and indices}

$G \quad$ Set of all generators, indexed by $g$

$G_{D} \quad$ Set of all dispatchable generators, $G_{D} \subset G$

$G_{R} \quad$ Set of all renewable generators, $G_{R} \subset G$

$S \quad$ Set of all storage technologies, indexed by $s$

$T \quad$ Set of all time steps, indexed by $t$

\section{Parameters}

$F C_{g} \quad$ Fixed unit cost of generator $g, € / \mathrm{MW}$.

$F C_{s}^{E} \quad$ Fixed unit cost of energy capacity for storage $\beta_{s, t}$ technology s, €/MWh.

$F C_{s}^{P} \quad$ Fixed unit cost of power capacity for storage $\gamma_{s, t}$ technology $s, € / \mathrm{MW}$.

$V C_{g} \quad$ Variable generation cost of generator $g, € / \mathrm{MWh} . \quad \delta_{s, t}$

$E P_{s} \quad$ Energy to Power ratio of storage unit $s, \mathrm{Wh} / \mathrm{W}$.

VOLL Value of Lost Load, $€ / \mathrm{MWh}$

$\Delta T \quad$ Time resolution, $\mathrm{h}$.

$D_{t} \quad$ Electricity demand at time step $t, \mathrm{MW}$.

$\widehat{D} \quad$ Peak electricity demand, MW.

$\eta_{s} \quad$ Round-trip efficiency of storage unit $s$, - .

$C F_{g, t} \quad$ Capacity factor of technology $g$ at time step $t$ of day $i$, - .
$C C_{S} \quad$ Capacity contribution of storage technology $s,-$

PRM Planning reserve margin ,-

\section{Variables}

$\operatorname{cap}_{g} \quad$ Installed capacity of generator $g, \mathrm{MW}$.

$\operatorname{cap}_{s}^{E} \quad$ Installed energy capacity of storage technology $s$, $\mathrm{MWh}$.

$\operatorname{cap}_{S}^{P} \quad$ Installed power capacity of storage technology $s$,

MW.

gen $_{g, t}$ Electricity generation of generator $g$ at time step $t$, $M W h / h$.

$c h_{s, t} \quad$ Charged quantity of storage technology $\mathrm{s}$ at time step $t, M W h / h$.

$d c_{s, t} \quad$ Discharged quantity of storage technology $\mathrm{s}$ at time step $t, M W h / h$.

$e_{s, t} \quad$ Energy level of storage technology s at time step $t$, MWh.

ens $s_{t} \quad$ Energy not served at time step $t, M W h / h$.

\section{Dual variables}

$\lambda_{t} \quad$ Dual variable associated with the energy balance constraint at time step $t, € / M W h$.

$\mu_{g, t} \quad$ Dual variable associated with the generation capacity constraint of dispatchable technology $g$ at time step $t, € / M W$.

$v_{g, t} \quad$ Dual variable associated with the generation capacity constraint of iRES technology g at time step $t, € / M W$.

$\alpha_{s, t} \quad$ Dual variable associated with the charge capacity constraint of technology $s$ at time step $t, € / \mathrm{MW}$. Dual variable associated with the discharge capacity constraint of technology $s$ at time step $t, € / \mathrm{MW}$. Dual variable associated with the energy capacity constraint of technology $s$ at time step $t, € / M W h$.

Dual variable associated with the constraint tracking the state of charge of storage technology $s$ at time step $t, € / M W h$.

$\pi_{t} \quad$ Dual variable associated with the PRM constraint, $€ / \mathrm{MW}$. 


\section{Introduction}

Energy storage technologies are key-enablers of a cost-efficient transition to and operation of decarbonized power systems with high shares of electricity generation from intermittent renewable energy sources (iRES). These storage assets may provide ancillary services, energy arbitrage on wholesale markets, transmission investment deferral, etc. [1]. In this paper, however, we focus on the benefits of the storage capacity in ensuring generation adequacy in high iRES-systems.

Typically, long-term planning models such as TIMES [2] and ReEDS [3] include a so called planning reserve margin (PRM) constraint to ensure a pre-defined level of firm capacity. This is necessary since the temporal representation often is restricted to a limited number of representative days with a low temporal resolution. As a consequence, the peak demand is typically underestimated, which may result in inadequate capacity mixes. In such a PRM constraint, capacity credits are used to reflect each technology's contribution to reaching the targeted level of firm capacity. In the same vain, capacity markets typically require participants to declare their availability during periods of peak demand, i.e., a capacity credit [4].

The capacity credit is a well-established concept for conventional and renewable generators (see, e.g., $[5,6])$, and is often broadly defined as the share of a generator's nameplate capacity that can be relied on during critical peak moments [7]. Methods to calculate the capacity credit are traditionally categorized in two groups, i.e., (i) the reliability-based methods and (ii) the approximation-based methods [8]. Well-known examples of reliability-based metrics are the effective load carrying capability (ELCC), equivalent firm capacity (EFC) and equivalent conventional power (ECP) [9]. Approximation-based methods entail amongst others, the Z-method $[10,11]$ and capacity factor approximations $[12,13]$.

Recently, a first set of studies has extended these traditional capacity credit estimation methods to storage technologies. Parks [14] uses a modified ELCC method in which the author explicitly allocates the energy-limited capacity to the hours with the highest loss of load probability (LOLP). Tuohy \& O'Malley [15] use a unit-commitment model to optimize the dispatch of a pumped hydro storage (PHS) unit at each hour. They use an approximation method to calculate the capacity credit of storage based on the average state-of-charge during 100 peak hours. A similar approach is adopted by Madaeni et al. [16] for determining the capacity credit of a concentrated solar power (CSP) plant with thermal energy storage (TES). Shioshansi et al. [17] improve these approaches by taking into account the effect of system shortages on the dispatch of the considered storage unit. These traditional capacity credit calculations are mostly performed for a pre-defined storage unit with a fixed size in a well-defined power system. As the underlying power system is a main driver for the effective capacity credit of a technology, these calculation methods are of limited practical use for a planning model, since the underlying power system is not a priori known.

Capacity credits are often interpreted as an asset's potential to reduce the peak (residual) load. Interestingly, there is also a second function attached to the capacity credit when used in a PRM constraint or a capacity market. As will be shown, the capacity credit also determines the implicit capacity payment attributed to each technology. This is obvious for applications in the context of capacity markets [21], but as discussed below, this effect is implicitly present in the context of longterm planning models as well. It is therefore key that the correct capacity credit value is used, as inaccurately representing the system value of capacity can lead to technology biases. This impact was already investigated for intermittent renewable energy sources by Bothwell \& Hobbs [4], but in this paper we aim to focus on storage technologies. 
The main goal of this paper is to approach the capacity credit concept from both the perspective of the potential to reduce the peak residual load (contribution to the capacity target), as well as the value of the capacity to the system. Contrary to conventional generators, these two capacity credit interpretations are not equivalent for some technologies. Especially when technologies are predominantly constrained by energy limitations (e.g., short-term storage technologies) there is a discrepancy between a storage technology's contribution to a capacity target and its value to the power system. Our analysis points out that, for storage technologies, the former is typically higher than the latter for the same storage investment. As demonstrated in a stylized case study, the implication of this finding is that reflecting the firm capacity contribution of a storage technology is likely to result in overvaluations of this technology, hence, overinvestments. On the contrary, correctly reflecting a storage technology's monetary value in the system triggers the cost-optimal amount of storage investments, but underestimates its true contribution to the capacity target. As a result, this leads to overinvestments in conventional peaking capacity.

The remainder of the paper is structured as follows. Section 2 introduces the two capacity credit interpretations. In Section 3, a standard cost-minimizing planning model that includes storage investments is analyzed. Next, Section 4 provides a conceptual illustration of both capacity credit interpretations specifically for storage technologies. In section 5 , a case study is performed with the model from Section 3. Finally, the conclusions are formulated in Section 6.

\section{Introducing two capacity credit interpretations}

Two interpretations of the capacity credit are at the core of this paper. Both interpretations are graphically summarized by Figure 1 . Note that for now, our illustrations are not specifically tailored to storage technologies, but are rather generally valid to any technology (the interpretation for storage technologies follows in Section 4).

The first interpretation is the capacity credit as a reflection of a technology's peak load reduction potential. The left hand side of Figure 1 illustrates this interpretation by means of residual load duration curves. Suppose a technology with a power capacity of $x$ is added to a power system that is characterized by a residual load duration curve (RLDC). By adding (and efficiently operating) $x$, the original RLDC changes $\left(R L D C_{\chi}\right)$, so that the residual load peak is shifted downwards. Suppose that the amount by which the peak load is reduced, is equal to $\bar{x}$. Then, the capacity credit based on the peak load reduction $\left(C C^{P L R}\right)$ can be expressed as the ratio between the reduction in peak load and the power capacity of the technology $(\bar{x} / x)$. 

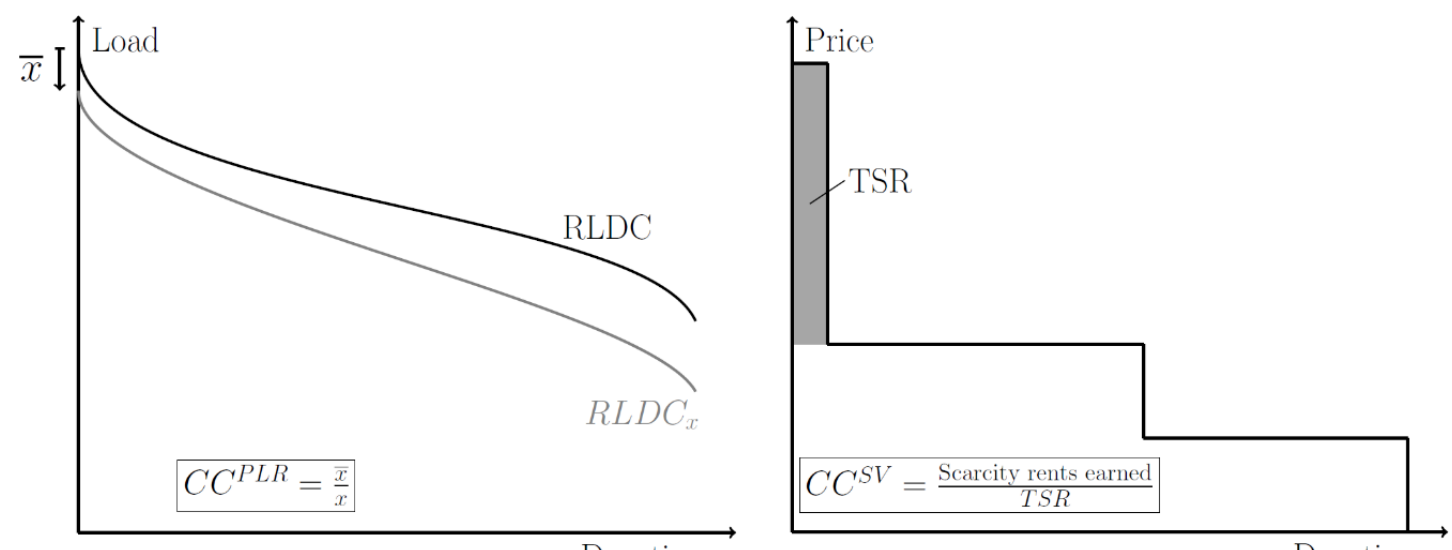

Duration

Duration

Figure 1: Illustration of the two capacity credit interpretations investigated in this paper, namely the capacity credit as a reflection of the peak load reduction (left) and the capacity credit based on the scarcity values (right).

The second interpretation is value-based and can be illustrated in a general manner by means of a price duration curve (right hand side of Figure 1). We know from basic electricity economics that in a cost-optimal capacity mix, the electricity price exceeds the marginal cost of the peak generator (typically to reach the VOLL) for a limited amount of time, so that the total scarcity rents earned by the peak generator offset its fixed costs [22]. These total scarcity rents (TSR) are indicated by the grey area in Figure 1. Of course, every technology active in the power system can earn scarcity rents during moments of scarcity. As such, one can express the capacity credit of a technology as the scarcity rents earned by that technology relative to the total scarcity rents that could potentially be earned. This capacity credit is labeled as $C C^{S V}$, where SV stands for scarcity value.

Both interpretations of the capacity credit become smaller than one when a technology cannot provide electricity at its rated capacity during critical peak periods. The most well-known example of this are the capacity credits of renewable technologies of which the power output are weather dependent. The limiting factor for storage technologies to receive a capacity credit equal to 1 , is their energy capacity, as will be shown in Section 4.

In literature traces of both capacity credit interpretations can be found. Regarding the first interpretation, Frazier et al. [18] use a dispatch model to determine the energy capacity requirements of a storage technology in order to reduce the peak demand by an amount equal to the installed power capacity. Furthermore, they use the Regional Energy Deployment System (ReEDS) generation expansion model to determine the cost optimal storage mix consisting of different storage durations for which the capacity credit is equal to one. A similar definition is used by Denholm et al. [19] in which the authors explicitly refer to the storage capacity credit as the 'peak demand reduction credit' (PDRC). The paper assesses the potential of battery storage technologies to provide peaking capacity for 18 regions in the United States by assessing the size of the battery-mix (consisting of technologies with an energy-to-power (E/P) ratio of 4,6 and $8 \mathrm{Wh} / \mathrm{W}$ ) with a PDRC equal to $100 \%$. Their analysis points out that storage technologies can provide significant capacity contributions and that the shape of the residual load patterns are a key determining factor.

Although not explicitly labeled as such, the second interpretation is sometimes encountered in the context of capacity markets. To ensure that all potential capacity providers compete on a level-playing 
field, capacity credits must reflect the actual contribution towards the targeted capacity level [20]. This is important as misrepresenting the true capacity credits can lead to technology biases. In this regard, Bothwell \& Hobbs [4] investigate the possible distortions that can emerge when capacity credits fail to capture the true capacity value for intermittent renewable energy sources. As they point out, using an iRES capacity credit that is higher than its true value results in an implicit subsidy and causes overinvestments in the iRES technology at hand. Likewise, underestimating the capacity credit disincentivizes investment in the considered iRES technology.

As will be shown, there is a discrepancy between both capacity credit interpretations when technologies have a decreasing capacity contribution in function of their penetration in the power system. This is definitely the case for RES and storage technologies, but often not for conventional technologies where the capacity credits are usually fairly constant and related to the forced outage rate.

Furthermore, the capacity credit-parameter used in planning reserve margin constraints should always reflect (i) the contribution of a technology towards the imposed capacity target, i.e., the peak load reduction, and (ii) the value associated with the capacity of the technology at hand. Of course, due to the discrepancy, both functionalities cannot be unified by a single parameter for storage technologies which can cause technology biases to occur. In this context, this paper aims to contribute to the existing literature by:

1. Conceptually illustrating the two functions of capacity credit-parameters in a PRM-constraint, i.e., the peak reduction potential and the scarcity value of the capacity. Furthermore, we explain the discrepancy between these two interpretations when applied to energyconstrained storage technologies.

2. Performing a case study to exemplify the distortions that emerge when either $C C^{P L R}$ or $C C^{S V}$ is used. In a sense, we point towards similar effects for storage technologies that Bothwell \& Hobbs [4] identified for renewable technologies. 


\section{Optimal investment in storage technologies}

This section introduces a basic planning model and analyzes its first-order optimality conditions. This model will be used in the conceptual illustrations (Section 4) and the case study (Section 5).

Equations (1) to (9) comprise the mathematical formulation of the planning model with storage technologies. ${ }^{1}$ In this paper, we restrict our analysis to storage technologies for which the power capacity relates to the energy capacity through the energy-to-power-ratio $\left(\operatorname{cap}_{S}^{P}=\frac{\operatorname{cap}_{S}^{E}}{E P_{S}}\right)$ and we assume that no variable costs are associated with operating storage technologies (besides energy losses). Note that the optimization problem below is also reflective of the behavior of price-taking investors participating in a perfectly functioning energy and capacity market [4].

$$
\begin{aligned}
\operatorname{Min} \sum_{g \in G} F C_{g} \cdot \operatorname{cap}_{g} & +\sum_{s \in S} F C_{s}^{E} \cdot c a p_{s}^{E}+\sum_{s \in S} F C_{s}^{P} \cdot \frac{c a p_{s}^{E}}{E P_{S}} \\
& +\sum_{t \in T}\left(\sum_{g \in G_{D}} V C_{g} \cdot g e n_{g, t} \cdot \Delta T+V O L L \cdot \text { ens }_{t} \cdot \Delta T\right)
\end{aligned}
$$

Subject to:

$$
\begin{array}{ccc}
\sum_{g \in G} g e n_{g, t}+\sum_{s \in S} d c_{s, t}-\sum_{s \in S} c h_{s, t}+e n s_{t}=D_{t} & \forall t \in T & \left(\lambda_{t}\right) \\
g e n_{g, t} \leq c a p_{g} & \forall g \in G_{D}, t \in T & \left(\mu_{g, t}\right) \\
g e n_{g, t} \leq C F_{g, t} \cdot \operatorname{cap}_{g} & \forall g \in G_{R}, t \in T & \left(v_{g, t}\right) \\
c h_{s, t} \leq \frac{\operatorname{cap} p_{s}^{E}}{E P_{S}} & \forall s \in S, t \in T & \left(\alpha_{s, t}\right) \\
d c_{s, t} \leq \frac{\operatorname{cap} p_{s}^{E}}{E P_{S}} & \forall s \in S, t \in T & \left(\beta_{s, t}\right) \\
e_{s, t} \leq c a p_{s}^{E} & \forall s \in S, t \in T & \left(\gamma_{s, t}\right) \\
e_{s, t+1}=e_{s, t}+\sqrt{\eta_{s}} \cdot c h_{s, t} \cdot \Delta T-\frac{d c_{s, t}}{\sqrt{\eta_{s}}} \cdot \Delta T & \forall s \in S, t \in T & \left(\delta_{s, t}\right) \\
\sum_{g \in G} C C_{g} \cdot \operatorname{cap}_{g}+\sum_{s \in S} C C_{s} \cdot \frac{\operatorname{cap} p_{s}^{E}}{E P_{s}} \geq(1+P R M) \cdot \widehat{D} &
\end{array}
$$

The objective function (Eq. (1)) expresses the total fixed and variable cost associated with investing in, and operating of a power system. The total fixed cost associated with non-storage technologies, indexed by $g$, is equal to the sum over all technologies, of the fixed unit cost $\left(F C_{g}\right)$ times the installed capacity of technology $g\left(\mathrm{cap}_{\mathrm{g}}\right)$. The variable cost of a non-storage technology at a particular time step is defined as the product of the average generation cost $\left(V C_{g}\right)$ and the generation of that technology at time step $t\left(g e n_{g, t}\right)$. For storage technologies, indexed by $s$, the total fixed costs are divided in the fixed costs associated with the energy and power components of the storage unit. The total fixed cost associated with the energy components is equal to the sum over all storage technologies of the fixed unit cost of energy capacity $\left(F C_{S}^{E}\right)$ times the installed energy capacity of the technology $\left(\mathrm{cap}_{S}^{E}\right)$, whereas the total fixed cost associated with the power components is equal to the sum over all storage technologies of the fixed unit cost of power (charge/discharge) capacity $\left(F C_{S}^{P}\right)$ times the installed power capacity of the technology, which is expressed here as the energy capacity

\footnotetext{
${ }^{1}$ For brevity, the non-negativity constraints are omitted, but all variables can only be greater than or equal to zero.
} 
divided by the energy-to-power-ratio $\left(E P_{S}\right)$. For the sake of simplicity, it is assumed that no variable operation costs are associated with storage technologies. Finally, there is a cost associated with energy not served $\left(e n s_{t}\right)$ which is equal to the value of lost load (VOLL). ${ }^{2}$

Constraint (2) is the power balance constraint, which expresses that the electricity demand minus energy not served (ENS) at each time step should be covered by electricity generation. Constraints (3) and (4) respectively limit the generation variables of dispatchable and renewable technologies. For renewable technologies, the generation is linked to the installed capacity via a normalized generation profile $\left(C F_{g, t}\right)$ to capture the intermittent nature of these resources. Constraints (5) and (6) limit the charge $\left(c h_{s, t}\right)$ and discharge $\left(d c_{s, t}\right)$ variables of storage technologies to their installed power capacity, while constraint (7) limits the energy level $\left(e_{s, t}\right)$ to the installed energy capacity. Finally, the intertemporal constraint (8) tracks the energy level between timesteps. The PRM constraint (9) makes sure that the total installed firm capacity exceeds the peak demand $(\widehat{D})$ by a margin (PRM).

The dual variable of the power balance constraint (Eq. (2)), i.e., $\lambda_{t}$ can be thought of as the electricity price that would emerge from a perfectly competitive day-ahead market ${ }^{3}$ in which all technologies $g \in G$ and $s \in S$ would participate. Similarly, $\pi$ reflects the price emerging on a perfectly competitive capacity market expressed by the PRM constraint. Furthermore, the dual variables associated with constraints (5), (6) and (7), i.e., $\alpha_{s, t}, \beta_{s, t}$ and $\gamma_{s, t}$ respectively reflect the operating monetary rents associated with additional charging, discharging and energy capacity.

The optimal solution is governed by a set of first-order optimality conditions. A full derivation of the first-order optimality conditions can be found in the Appendix. For brevity, we restrict ourselves to the condition that defines an optimal investment in storage technologies in the body of the paper. We identify two cases:

1. No PRM constraint is used (Eq. (1) - (8))

$$
F C_{s}^{E}+\frac{F C_{s}^{P}}{E P_{s}}=-\sum_{t \in T}\left[\gamma_{s, t}+\frac{\alpha_{s, t}+\beta_{s, t}}{E P_{s}}\right]
$$

Equation (10) expresses that in an optimal solution, the cost per unit of energy capacity must equal the total economic rents earned per unit of energy capacity by arbitraging energy. Note that all terms in Equation (10) are expressed per unit of energy capacity. To obtain the same expression per unit of installed power capacity, we only need to multiply both sides by the energy-to-power ratio.

$$
F C_{s}^{E} \cdot E P_{s}+F C_{s}^{P}=-\sum_{t \in T}\left[\gamma_{s, t} \cdot E P_{s}+\alpha_{s, t}+\beta_{s, t}\right]
$$

Recall that since no PRM constraint is introduced, the right hand side contains scarcity rents, i.e., rents earned by discharging at times where the electricity price $\left(\lambda_{t}\right)$ exceeds the marginal cost of the peak generator.

2. A PRM constraint is used (Eq. (1) - (9))

$$
F C_{s}^{E} \cdot E P_{S}+F C_{s}^{P}=-\sum_{t \in T}\left[\gamma_{s, t} \cdot E P_{s}+\alpha_{s, t}+\beta_{s, t}\right]+C C_{s} \cdot \pi
$$

\footnotetext{
2 If the PRM constraint is binding, no load shedding emerges in the final solution.

${ }^{3} \mathrm{~A}$ market operated with perfect information, no barriers of entry and no price caps.
} 
Similar to Eq. (11), Eq. (12) expresses the equivalence between the fixed costs per unit of capacity and the total rents earned per unit of capacity. However, due to the introduction of the PRM constraint, the total rents are split in the rents earned by arbitraging energy and a capacity payment. Note that, under typical assumptions, the PRM constraint becomes binding and no scarcity prices emerge in the energy only market and the energy arbitrage rents only constitute the inframarginal rents.

It is evident from Eq. (9) that the function of the capacity credit is to reflect the fraction of the total installed capacity that can contribute to the imposed firm capacity target. In this context, the capacity credit has a strong connection to metrics that reflect peak reduction potential and it seems straightforward that $C C^{P L R}$ should be used. However, the second function of the capacity credit becomes visible when observing the first-order optimality condition expressed by Eq. (12). Here we see that the capacity credit determines the implicit capacity payment attributed to storage technologies. In this regard, to make sure that the same incentives are provided the capacity credit should be chosen in such a way that the latter term in Eq. (12) offsets all scarcity rents earned by the storage unit. From this perspective $C C^{S V}$ would be the obvious choice to reflect the capacity contribution of storage technologies. In the following section, we will show how the capacity credit of storage may be determined, following the two different interpretations, and how the resulting values may differ.

\section{Capacity credits of storage technologies}

\subsection{Capacity credit as a reflection of the peak reduction potential}

To decrease the peak residual load of a power system, a storage unit is limited by the installed power capacity as well as the installed energy capacity. This is different from conventional technologies which usually do not have such stringent energy constraints.

In order to illustrate the effect of the energy capacity on the capacity contribution of storage observe the peak residual demand, $d(t)$, depicted in Figure $2 \mathrm{a}$ and $2 \mathrm{~b}$ and suppose a storage unit with power capacity $x$ is installed. Figure 2 a shows a situation in which the energy capacity of the storage unit is sufficiently large to sustain a continuous discharge over the entire peak period. In this situation, the storage unit is able to reduce the peak load as much as the power capacity allows and the capacity credit, i.e., $C C^{P L R}$ (peak reduction relative to installed power capacity) is equal to 1 .

We now define the minimally required energy capacity (MREC) as the energy capacity that is needed for a storage unit to receive a capacity credit of 1 . This minimally required energy capacity is equal to the orange colored area depicted Figure $1 \mathrm{a}$ and can be expressed mathematically as:

$$
M R E C=\int_{t 1}^{t 2}(d(t)-\widehat{D}+x) d t
$$

It is evident from Eq. (13) that the MREC depends on the residual demand, which in turn depends on the demand and the renewable generation. Furthermore, acknowledging the fact that $t 1$ and $t 2$ depend on the installed power capacity $x$, the MREC is also a function of the installed power capacity $x .{ }^{4}$ The orange curves depicted in Figures $2 \mathrm{c}$ and $2 \mathrm{~d}$ show the MREC associated with the illustrative residual demand profile depicted in Figure $2 a$. Note that the MREC as defined here, represents the same requirement as used by Frazier et al. [18] to determine the energy capacity necessary to receive full capacity credit, i.e., a capacity credit equal to one.

\footnotetext{
${ }^{4}$ The derivations and illustrations presented here assume a peak period that contains a single residual demand peak, but note that can be extended to peak periods that consist of two or more consecutive residual demand peaks.
} 
At the same time, if the true installed energy capacity (compensated for the discharge losses) is less than the MREC, the storage unit is not able to reduce the peak residual demand as much as the installed power capacity and the capacity credit is less than one. Such a situation is depicted in $2 \mathrm{~b}$. As can be seen, the energy capacity is less than the MREC which results in a peak load reduction of only $\bar{x}$. The true available installed energy capacity $(E C)$ of the storage unit also is a function of the installed power capacity, i.e., it is a linear function with a proportionality constant equal to the product E/Pratio times the discharge efficiency (square root of the round-trip efficiency).

$$
E C=\sqrt{\eta} \cdot E P \cdot x
$$

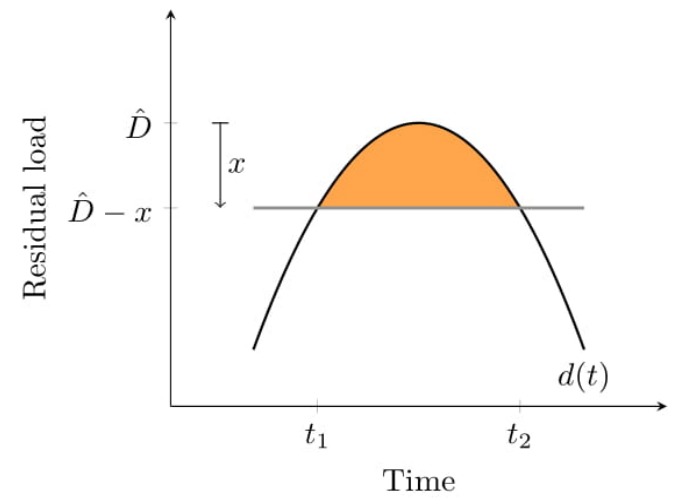

(a)

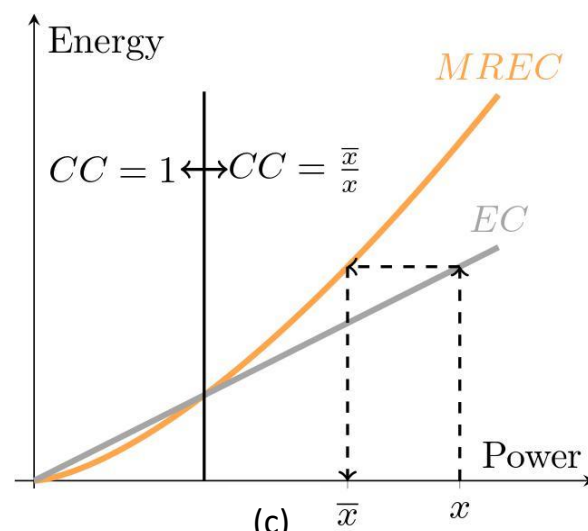

(c) $\bar{x}$

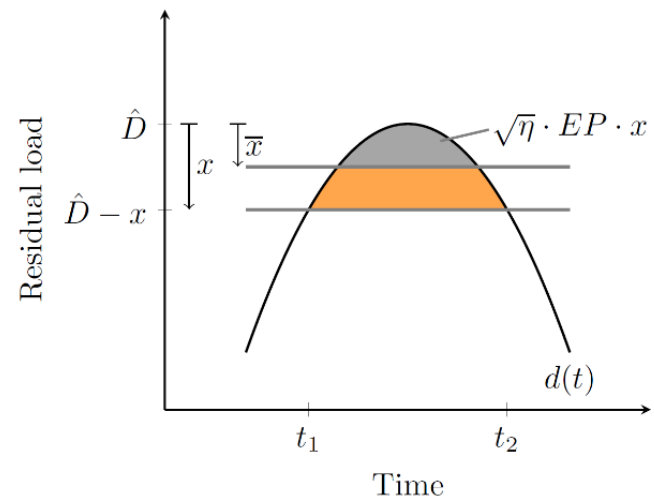

(b)

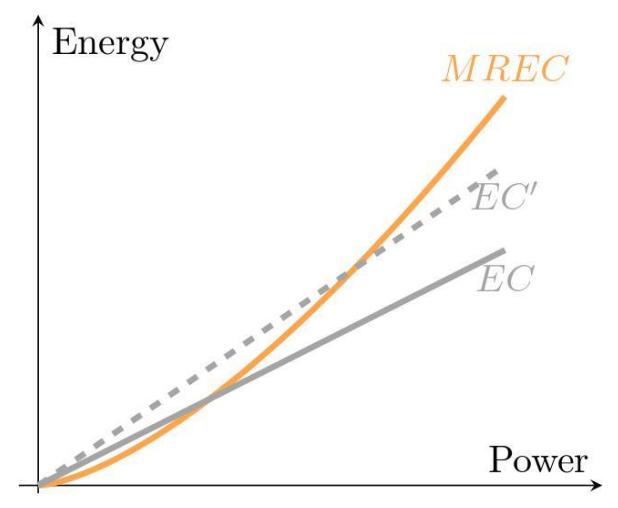

(d)

Figure 2: Illustration of the impact of the installed energy capacity on the ability of a storage unit to decrease the peak residual demand $(d(t))$. If the energy capacity is sufficiently high a storage unit can de crease the peak residual demand as much as the installed power capacity $x$ (Fig. 2a). However, when the installed energy capacity $(E P \cdot x)$ is insufficient, the peak reduction potential decreases to $\bar{x}$ (Fig. 2b). As long as the installed energy capacity (EC, grey lines) exceeds the minimally required energy capacity (MREC, orange lines), the capacity credit is equal to 1 . If the $M R E C$ exceeds the EC the capacity credit is smaller than one (Fig 2c). Storage technologies with a higher E/P-ratio are able to maintain a capacity credit of one for higher penetrations (Fig. 2d). 
The grey line in Figure $2 c$ reflects the installed energy capacity determined by Eq. (14). For a low storage penetration the installed energy capacity exceeds the MREC resulting in a capacity credit that is equal to 1 . As the storage power capacity increases, the installed energy capacity starts to constrain the peak reduction potential of the storage technology and only a peak reduction of $\bar{x}$ can be achieved for an installed power capacity of $x$. As such, $C C^{P L R}$ is equal to $\frac{\bar{x}}{x}<1$.

Furthermore, Figure $2 d$ illustrates the energy capacity in function of the installed power capacity for two different E/P-ratios. It is apparent from this figure that a storage technology with a higher E/Pratio (dashed lines) is capable of maintaining a capacity credit of one for higher storage penetrations.

\subsection{Capacity credit as a reflection of the scarcity value}

As explained in Section 2, the second interpretation of the capacity credit corresponds to the scarcity rents earned by the storage unit relative to the total scarcity rents. To identify the scarcity rents, we rewrite Eq. (11) by distinguishing between rents earned during non-scarcity and scarcity moments. Scarcity moments are characterized by an electricity price that is greater than the marginal cost of the peak generator $V C_{\hat{g}}$. By acknowledging that charging during scarcity moments does not occur in an optimal dispatch, the RHS of Eq. (11) becomes:

$$
-(\underbrace{\sum_{t \in T: \lambda_{t} \leq V C_{\hat{g}}}\left[\gamma_{s, t} \cdot E P_{s}+\alpha_{s, t}+\beta_{s, t}\right]}_{\text {non-scarcity rent }}+\underbrace{\sum_{t \in T: \lambda_{t}>V C_{\hat{g}}}\left[\gamma_{s, t} \cdot E P_{s}+\beta_{s, t}\right]}_{\text {scarcity rent }})
$$

To preserve the same incentives for storage technologies when introducing the PRM constraint, the appropriate capacity credit value can be derived by equating the latter terms of Eqs. (12) and (15). Acknowledging the fact that the dual variable $\pi$ equals the average fixed cost of the peak generator (i.e., the cost of new entry) which in turn is equal to the total scarcity rents (in the optimal solution), we can write the capacity credit of a storage unit as:

$$
\begin{gathered}
C C^{S V}=-\frac{\sum_{t \in T: \lambda_{t}>V C_{\hat{g}}}\left[\gamma_{s, t} \cdot E P_{s}+\beta_{s, t}\right]}{\pi} \cong-\frac{\sum_{t \in T: \lambda_{t}>V C_{\hat{g}}}\left[\gamma_{s, t} \cdot E P_{s}+\beta_{s, t}\right]}{F C_{\hat{g}}} \\
=-\frac{\sum_{t \in T: \lambda_{t}>V C_{\hat{g}}}\left[\gamma_{s, t} \cdot E P_{s}+\beta_{s, t}\right]}{T S R}
\end{gathered}
$$

To conceptually illustrate this capacity credit interpretation, observe the energy-constrained storage technology depicted in Figure 3. Assume furthermore that the peak shown is the only period in which capacity becomes scarce, so that the scarcity rents emerge as energy capacity rents (i,.e., $\beta_{s, t}=$ $0, \gamma_{s, t} \neq 0$ ). For this situation, the total rents earned by the storage technology (the numerator in Eq. (16)) during the scarcity hours can be written as the product of the energy contents times the instantaneous scarcity rents. Expressed relative to the installed power capacity $\mathrm{x}$, the numerator of (16) becomes:

$$
\text { Scarcity rents per } M W=\frac{\sqrt{\eta} \cdot E P \cdot x \cdot\left(V O L L-V C_{\hat{g}}\right)}{x}=\sqrt{\eta} \cdot E P \cdot\left(V O L L-V C_{\hat{g}}\right)
$$


The total scarcity rents that can be earned per MW (the denominator in Eq. (16)) can be expressed as $\left(V O L L-V C_{\hat{g}}\right) \cdot T$, where $\mathrm{T}$ is the duration of the peak. As such, the scarcity value-based capacity credit of the storage unit can be written as:

$$
C C^{S V}=\frac{\sqrt{\eta} \cdot E P}{T}
$$

For energy-constrained technologies the capacity credit is directly proportional to its E/P-ratio and roundtrip efficiency and is inversely proportional to the duration of the peak.

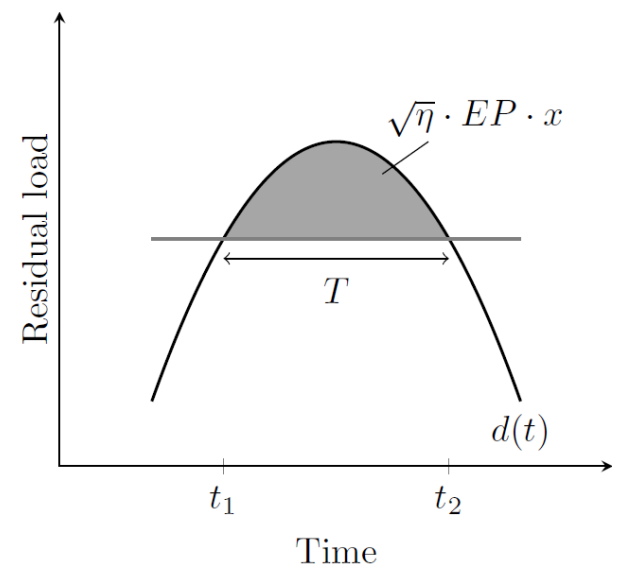

Figure 3: An energy-constrained storage technology during the residual load peak.

Equation (18) expresses the capacity credit for a storage technology that is energy-constrained during the peak period. For a storage technology that is completely power-constrained during the peak (i,.e., $\beta_{s, t} \neq 0, \gamma_{s, t}=0$ ), the storage technology discharges at full power capacity and hence, behaves as a conventional generator. As such, it is straightforward to see that in this case the capacity credit is equal to 1 if the technology is fully reliable.

\subsection{Comparison of the two capacity credit interpretations}

To illustrate the two capacity credit interpretations, an illustrative case study was conducted with the planning model of Section 3 (without PRM constraint) in which the storage power capacity $x$ is gradually increased (exogenously imposed). For this illustration hourly RES capacity factor and load profiles for the Belgian power system were used.

Figure 4 shows both capacity credit interpretation for a $4 \mathrm{Wh} / \mathrm{W}$-technology in a power system with a RES penetration of $40 \%$. Clearly, both interpretations are fundamentally different, which could also be expected by comparing the formulas for $C C^{P L R}\left(\frac{\bar{x}}{x}\right)$ and $C C^{S V}\left(\frac{\sqrt{\eta} \cdot E P}{T}\right)$. This raises the question of which capacity credit definition should be used in the context of a PRM constraint or a capacity market. Given that the capacity credit obtained by the peak reduction potential is greater than the capacity credit reflecting the true scarcity value of the storage capacity, two hypotheses can be formulated:

- Using the capacity credit based on the peak reduction potential in a PRM-constraint/capacity market correctly captures the capacity contribution of storage technologies, but implicitly overvalues storage technologies causing overinvestments.

- At the same time, using the second interpretation would accurately replicate the scarcity rents that would be earned in an energy-only market, but would also underestimate the true peak 
reduction potential. As such, including a PRM-constraint correctly values storage technologies, but underestimates their capacity contribution to the planning reserve margin which causes overinvestments in peak generators as compensation.

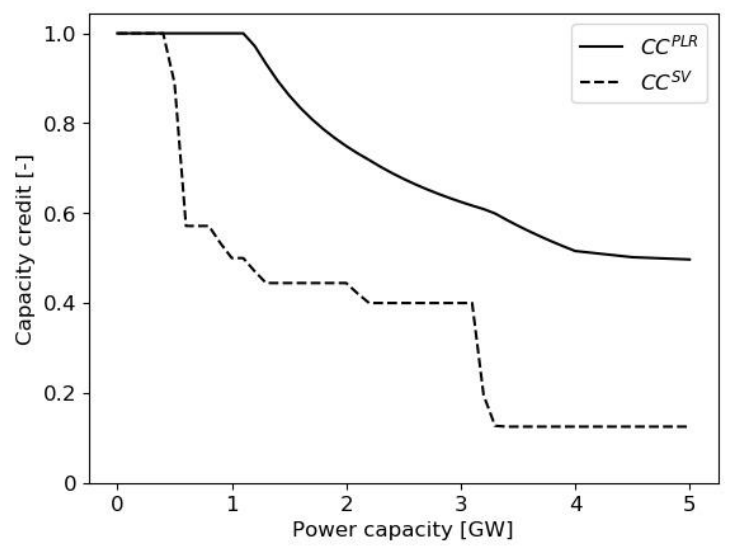

Figure 4: The evolution of $C C^{P L R}, C C^{S V}$ for a $4 W h / W$-technology in a power system with a RES penetration of $40 \%$. 


\section{Case study}

To test the two hypotheses identified in Section 4.3, a comparison is made between the results of (i) a full year endogenous optimization (see Eqs. (1)-(8)) and (ii) an optimization with a PRM constraint (see Eqs. (1)-(9)) in which the capacity credit of storage is either determined by the peak reduction potential or the scarcity value. Furthermore, we aim to bridge the perceived discrepancy between both capacity credit interpretations by introducing a penalty term in the objective function that compensates for the excess incentives provided by the capacity credit based in the peak reduction potential. The general setup of the case study is presented in Section 5.1 and the results are discussed in Section 5.2.

\subsection{General setup}

Please note that the aim is to demonstrate the distortions that can emerge from different capacity credit interpretations. As such, in order to facilitate a fair comparison we need to make sure that both models differ solely in this regard. The following methodology is used:

1. Determine the $C C^{P L R}$ and the $C C^{S V}$ curves for a power system with a fixed amount of renewables ${ }^{5}$. To this end, we run the planning model of Section 3 without PRM constraint for various fixed storage capacities. To make sure that storage is competitive, the amount of installed renewables is set to four times the Belgian installed capacity in 2020. The 2020 values are taken from Entso-e's transparency platform [23] and the imposed capacities are summarized in Table 1.

\begin{tabular}{cc} 
Technology & $\begin{array}{c}\text { Installed capacity } \\
{[\text { [GW] }}\end{array}$ \\
\hline Wind onshore & 8.9 \\
\hline Wind offshore & 6.4 \\
\hline Solar PV & 15.5
\end{tabular}

Table 1: Installed RES capacity used in the case study. Values correspond to four times the 2020 values reported on Entso-e's transparency platform [23].

2. Solve a full-year, hourly optimization with the optimization model described by Eqs. (1)(8) (without PRM constraint). The resulting capacity mix serves as a benchmark against which the other models' performance is measured. Hence, we refer to this as the reference case (ref). The installed capacities of wind onshore, wind offshore and solar PV are of course fixed and identical to the capacities from step 1.

3. Replace the scarcity time slices $^{6}$ (that determine the total installed capacity for the reference case) with off-peak time slices and impose a PRM-like constraint that determines the total installed firm capacity. The off-peak time slices are taken to be the time slices that precede each scarcity time slice by 24 hours. It is important here that the imposed capacity target corresponds with the firm capacity installed by the reference model. Furthermore, since the installed amount of renewables is fixed, the capacity constraint can be reduced to:

$$
\sum_{g \in G D} c a p_{g}+\sum_{s \in S} C C_{s} \cdot \frac{c a p_{s}^{E}}{E P_{S}} \geq C A P \text { Target }
$$

\footnotetext{
${ }^{5}$ Note that in a realistic case renewable technologies would compete alongside storage technologies in a planning model/capacity and energy market. However, to put the emphasis on the two capacity credit interpretations we assume the renewable penetration to be fixed.

${ }^{6}$ The number of scarcity time slices is typically lower than 10.
} 
The imposed capacity target is equal to the peak residual demand minus the load shedding (this is the part of the peak residual demand that is either covered by conventional generation or storage) that occurs in each reference case.

4. Iteratively solve the model with the capacity constraint until an equilibrium is reached between the imposed capacity credit and the observed capacity credit resulting from the optimization. This iterative procedure is illustrated in Figure $5 .{ }^{7}$ Three options for the choice of the capacity credit are investigated:

- Option 1: Iteratively solve using the $C C^{P L R}$ curve from step 1.

- Option 2: Iteratively solve using the $C C^{S V}$ curve from step 1.

- Option 3: Iteratively solve using the $C C^{P L R}$ curve, but add a penalty term $\varepsilon$ in the objective function that compensates for the excess incentives provided by this capacity credit interpretation. As we will show in our case study, this case represents the situation in which both the amount of firm capacity as well as the value of the storage technology are captured correctly.

$$
\varepsilon=\left(C C^{P L R}-C C^{S V}\right) \cdot \hat{\pi} \cdot \frac{c a p_{s}^{E}}{E P_{S}}
$$

In Eq. (20) $\hat{\pi}$ is an estimator for the value of the dual variable associated with the PRM constraint. As mentioned before, this value is likely equal to the fixed unit cost of the peak generator.

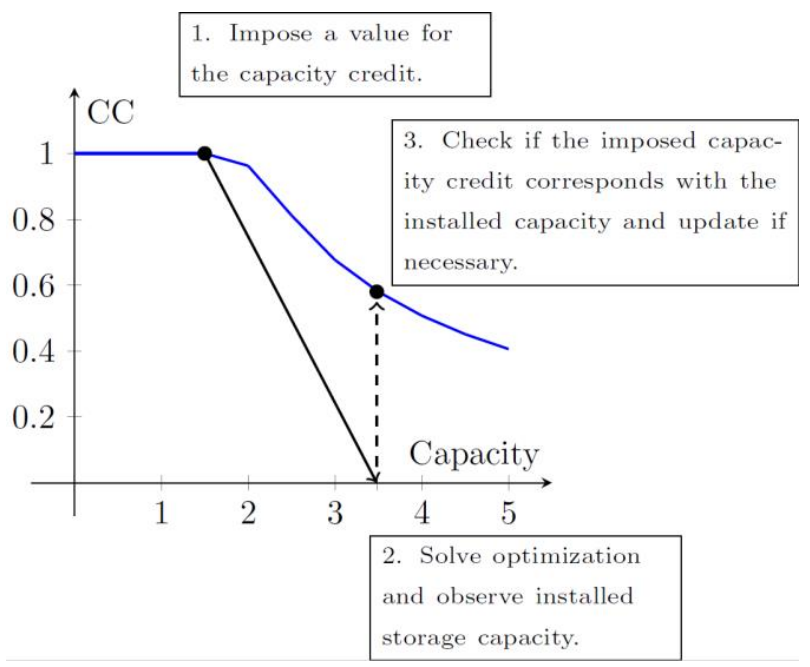

Figure 5: Illustration of the iterative procedure to determine the equilibrium capacity contribution. This iterative procedure continues until there is a correspondence between the imposed capacity credit and the installed storage capacity.

The usage of capacity credit curves as described above is not very practical when the amount of iRES is not a priori known since these curves depend on the underlying power system. In this paper the

\footnotetext{
${ }^{7}$ After a correspondence is reached between the imposed capacity credit and the observed capacity credit, it is checked whether the PRM is indeed a binding, i.e., that there is no scarcity that emerges in the energy balance.
} 
focus is on one storage technology at a time and we assume the iRES technologies to be fixed, these curves can be derived easily. Note that the methodology above can also be executed by evaluating the capacity credits (of any technology) for each capacity mix that emerges after every iteration of the planning model, rather than evaluating the capacity credits for all storage penetration levels in the first step. This approach would then resemble a capacity market auction described by Zachary et al. [21].

As illustrated below, the E/P-ratio has a large impact on the shape of the capacity credit curves. Therefore, the analysis is conducted for 4 storage technologies with E/P-ratios of $2 \mathrm{Wh} / \mathrm{W}, 4 \mathrm{Wh} / \mathrm{h}, 6$ $\mathrm{Wh} / \mathrm{W}, 8 \mathrm{Wh} / \mathrm{W}$. Table 2 and Table 3 list the input data used for respectively the considered generation technologies [24] and the storage technology [25]. Figure 6 illustrates the annualized fixed costs of storage technologies (in EUR/kW/a) as a function of the E/P-ratio and the fixed unit cost per unit of energy capacity. ${ }^{8}$ The orange markers indicate the annualized fixed costs of the technologies considered in this analysis.

Furthermore, renewable capacity factor profiles were taken from renewables.ninja [26,27] for Belgium the year 2016 and the Belgian load profile for that year was taken from Elia [28].

\begin{tabular}{|c|c|c|c|c|c|c|c|}
\hline Technology & $\begin{array}{c}\text { Investment } \\
\text { cost } \\
{[\mathrm{EUR} / \mathrm{kW}]}\end{array}$ & $\begin{array}{c}\text { FOM } \\
\text { [EUR/kW/a] }\end{array}$ & $\begin{array}{c}\text { VOM } \\
\text { [EUR/MWh] }\end{array}$ & $\begin{array}{c}\text { Fuel } \\
\text { [EUR/MWhp] }\end{array}$ & $\begin{array}{c}\mathrm{EF} \\
{\left[\text { ton } \mathrm{CO}_{2} / \mathrm{MWh}^{\mathrm{p}}\right]}\end{array}$ & $\begin{array}{l}\text { Lifetime } \\
\text { [years] }\end{array}$ & $\begin{array}{c}\text { Efficiency } \\
{[-]}\end{array}$ \\
\hline Base & 4283.5 & 60.2 & 3.5 & 7 & 0 & 60 & 0.33 \\
\hline Mid & 887.1 & 25.7 & 2.4 & 20 & 0.21 & 25 & 0.51 \\
\hline Peak & 611.5 & 12.0 & 2.4 & 20 & 0.21 & 25 & 0.34 \\
\hline
\end{tabular}

Table 2: Generation technology costs, efficiencies and lifetimes are based on [24]

\begin{tabular}{cccccc} 
Technology & $\begin{array}{c}\text { Investment } \\
\text { cost (energy } \\
\text { components) } \\
\text { [EUR/kWh] }\end{array}$ & $\begin{array}{c}\text { Investment } \\
\text { cost (power } \\
\text { components) } \\
{[\text { [EUR/kW] }}\end{array}$ & $\begin{array}{c}\text { VOM } \\
\text { [EUR/MWh] }\end{array}$ & $\begin{array}{c}\text { Lifetime } \\
\text { [years] }\end{array}$ & $\begin{array}{c}\text { Roundtrip } \\
\text { efficiency } \\
{[-]}\end{array}$ \\
\hline Battery & 150 & 85 & 0 & 15 & 0.85
\end{tabular}

Table 3: Battery storage costs, efficiency and lifetime are based on IRENA [25].

${ }^{8}$ Annualized values are calculated with a fixed cost of the power components of $85 \mathrm{EUR} / \mathrm{kW}$ and a lifetime of 15 years. 


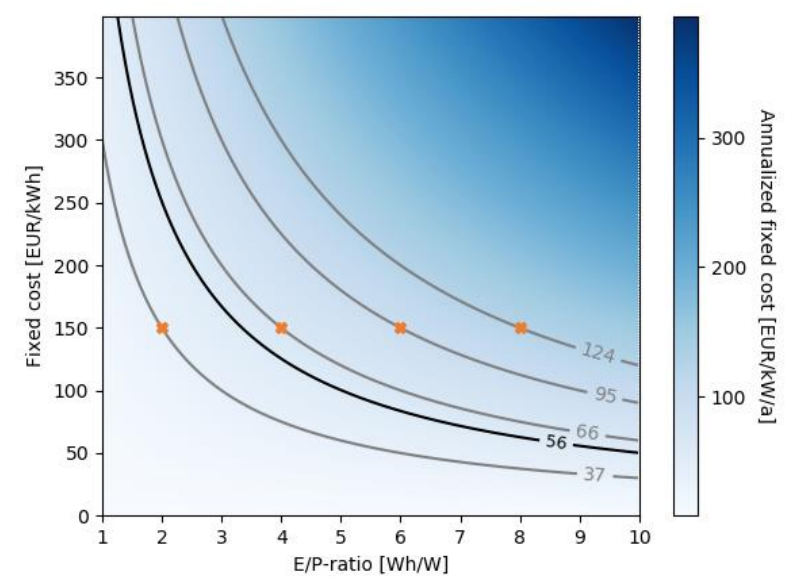

Figure 6: Annualized fixed costs of a storage technology with a lifetime of 15 years and as a function of per unit energy cost and the E/P-ratio. The black hyperbola resembles the points for which the annualized fixed cost is equal to the annualized fixed cost of the peak technology.

\subsection{Results}

\subsubsection{Reference case}

Figure 7 already indicated that the annualized fixed cost increases as the E/P-ratio increases. In this regard, the E/P-ratio also affects the extent to which storage emerges in the optimal solution. This is shown in Figure 7 which shows the technology choices for the reference case. Indeed, the storage penetration decreases for an increasing E/P-ratio due to higher investment costs. Furthermore, due to the high RES penetration (not shown on graph), no baseload investments are made.

As mentioned before, to ensure a fair comparison with the reference case, in the next step we need to impose capacity targets that facilitate the same amount of firm capacity (conventional and storage) to be installed. Table 4 lists the obtained capacity targets from each reference case, which is equal to the peak residual demand minus the load shedding at the peak residual demand time step.

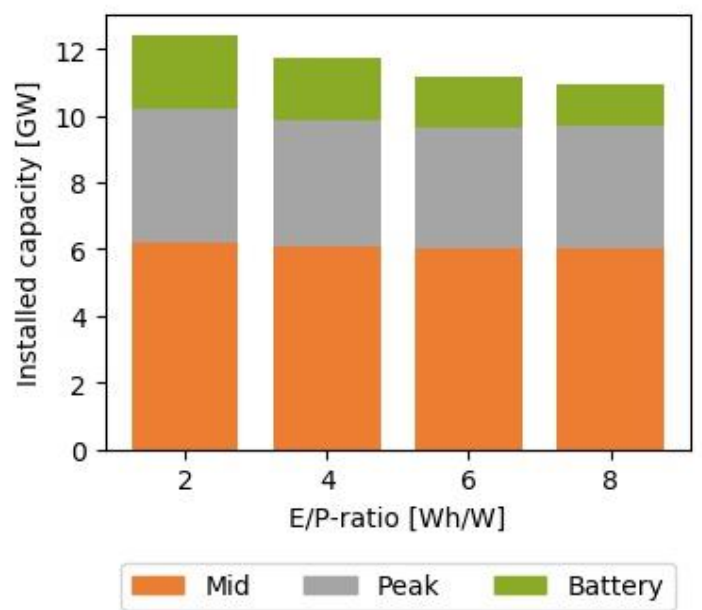

Figure 7: Technology choices obtained for the reference cases of the four considered E/P-ratios. 


\begin{tabular}{cc}
$\begin{array}{c}\text { Storage } \\
\text { technology }\end{array}$ & $\begin{array}{c}\text { Capacity target } \\
\text { [GW] }\end{array}$ \\
\hline $2 \mathrm{Wh} / \mathrm{W}$ & 11.32 \\
\hline $4 \mathrm{Wh} / \mathrm{W}$ & 11.32 \\
\hline $6 \mathrm{Wh} / \mathrm{W}$ & 11.17 \\
\hline $8 \mathrm{Wh} / \mathrm{W}$ & 10.91
\end{tabular}

Table 4: Capacity targets obtained for each reference case. The values are equal to the peak residual demand minus the load shedding at the peak residual demand time step.

\subsubsection{PRM results}

Using the capacity targets from Table 4 in Eq. (17), an iterative procedure is followed to determine the point at which the imposed capacity credit and the observed capacity credit correspond. Figure 8 shows the capacity credit curves (solid lines represent $C C^{P L R}$, while dashed lines represent $C C^{S V}$ ) for the different storage technologies in the considered power system. The cross markers indicate the equilibrium values of both the capacity credit based on the peak load reduction as well as the capacity credit based on the scarcity value. As expected, using the lower $C C^{S V}$-curve results in a smaller installed capacity of storage than the higher $C C^{P L R}$-curve. A comparison with the installed storage capacity of the reference case (dotted line) learns that the usage of the $C C^{P L R}$-curve results in higher storage investments, while using the $C C^{S V}$-curve triggers the same storage investments. Furthermore, the triangle marker shows the situation in which the $C C^{P L R}$-curve is used together with the additional penalty term $\varepsilon$ in the objective function to compensate for the excessive incentives provided by the $C C^{P L R}$-curve. As can be seen, the storage investments are reduced to the level of the reference case for all E/P-ratios. 

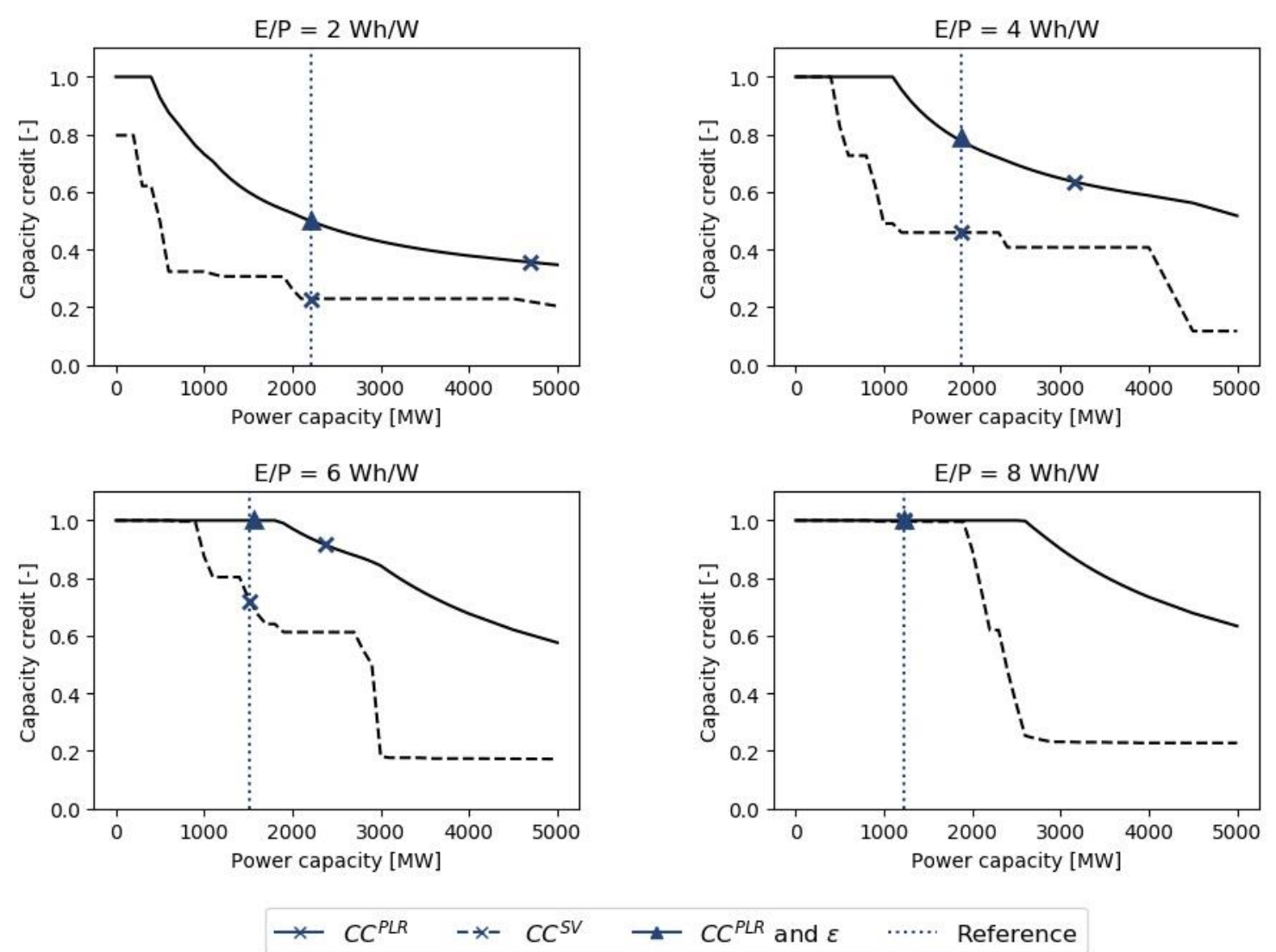

Figure 8: curves (solid lines represent $C C^{P L R}$, while dashed lines represent $C C^{S V}$ ) for the different storage technologies and power system considered in this case study. The markers indicate the values for which and equilibrium is reached, i.e., for which the imposed capacity credit value in the PRM constraint corresponds to the capacity credit associated with the installed storage capacity.

Figure 9 shows the differences in the obtained capacity mix with respect to each reference case (see Figure 7). As can be seen, the $C C^{P L R}$-curve consistently overvalues the installed storage capacity, which results in storage overinvestments with respect to the reference case. These overinvestments are larger for the low E/P-technologies, e.g., up to $2.5 \mathrm{GW}$ for the $2 \mathrm{Wh} / \mathrm{W}$-technology but only 1.3 $\mathrm{GW}$ for the $4 \mathrm{Wh} / \mathrm{W}$ technology and $0.85 \mathrm{GW}$ for the $6 \mathrm{Wh} / \mathrm{W}$-technology.

On the contrary, when using the $C C^{S V}$-curve the level of storage investments is almost identical to the reference case (variations are below $5 \mathrm{MW}$ ). This is not surprising since the capacity value curve corresponds to the scarcity rents that would be earned in an perfectly competitive energy-only market with a cost optimal capacity mix, i.e, the situation reflected in the reference case. However, since the $C C^{S V}$-curve does not capture the entire peak reduction potential of the installed storage unit (which is captured by the capacity credit) additional peak capacity is installed to compensate for this effect. Note that for the $8 \mathrm{Wh} / \mathrm{W}$-technology the same result is obtained as the reference case since the equilibrium capacity contribution is situated where both capacity credit definitions are equal to one.

Furthermore, Figure 9 shows that adding the penalty term $\varepsilon$ to compensate for the excess incentives provided by the $C C^{P L R}$-curve reduces the storage investments to the desired level of the reference case, while maintaining the of the correct contribution to the capacity target. The technology biases are largely eliminated. 


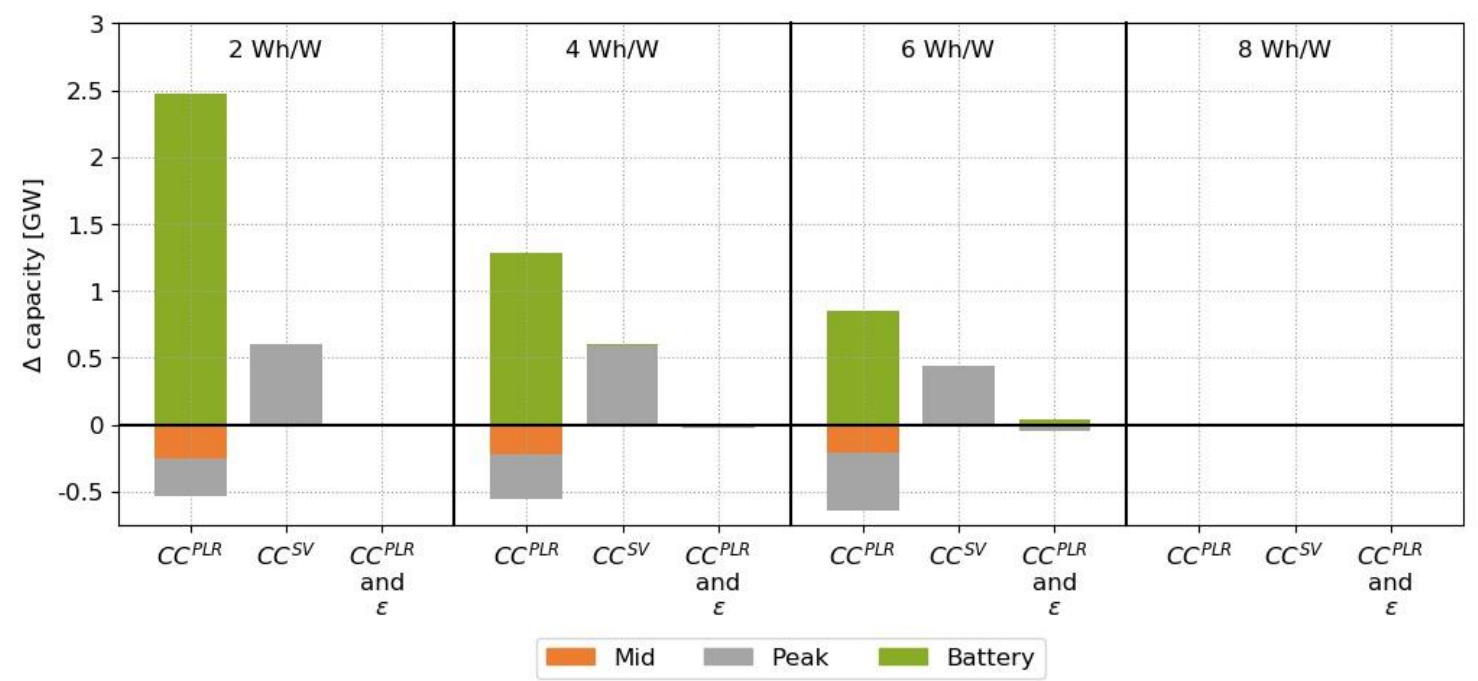

Figure 9: Differences in capacity mix obtained by using either the $C C^{P L R}$-curves or the $C C^{P L R}$-curves for each considered storage technology.

To elaborate on the storage bias introduced by the capacity credit, Figure 10 shows the (implicit) capacity payment that is implied by the imposed capacity contribution in the PRM constraint, i.e., the value of the latter term in Eq. (12), together with the scarcity rents actually earned in a perfectly competitive energy-only market (without PRM constraint). As the figure shows, when using the $C C^{P L R}$-curve there is a clear discrepancy between the two rents. This is the reason for the storage overinvestments when using the peak load reduction potential. For the other two cases, this discrepancy either does not exist ( $C C^{S V}$-curve) or is fully compensated by the penalty term $\left(C C^{P L R}\right.$ and $\left.\varepsilon\right)$, causing the same level of storage investments. These results suggest that storage owners might be in favor for implementing a capacity market if a peak load reduction-based capacity credit would be used, as this would result on capacity payments higher than the scarcity rents that would be earned in a perfectly competitive energy-only market . 


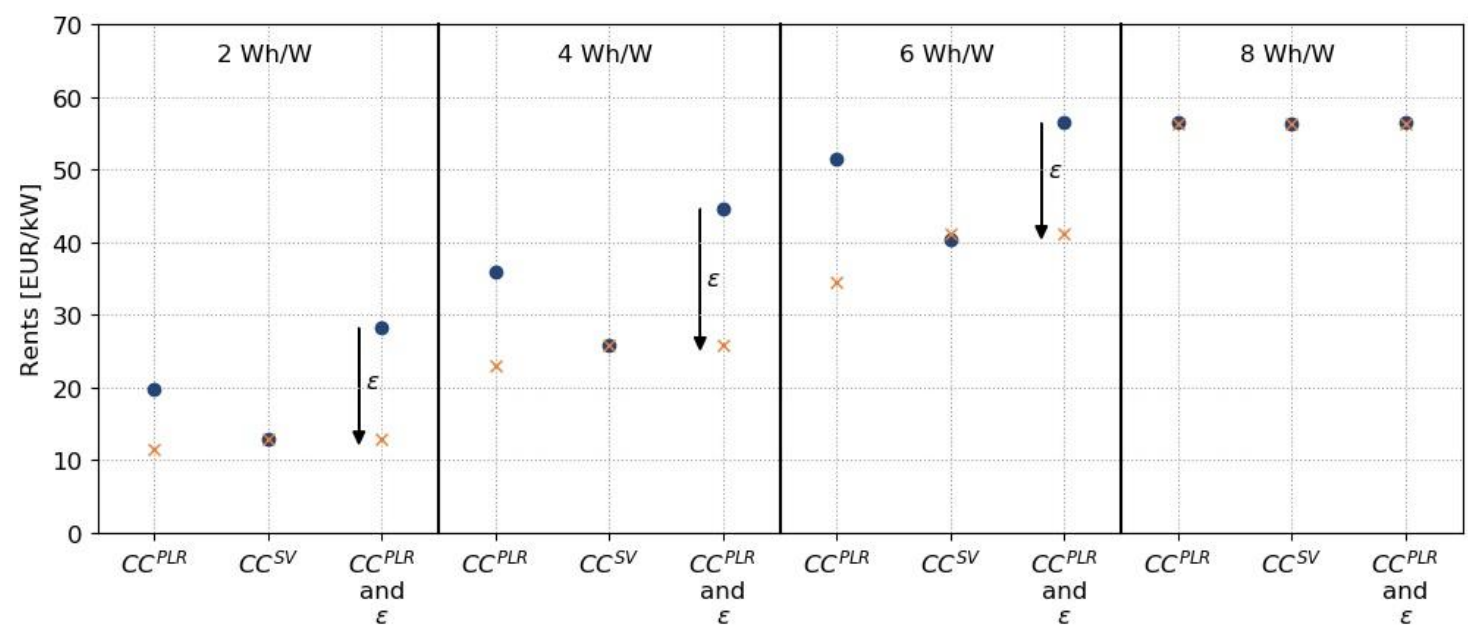

- Capacity payment implied in PRM $\times$ Scarcity rents earned in reference case

Figure 10: Capacity payment received by the storage technologies as implied in the PRM constraint by using either the capacity credit or the capacity value (blue markers), and scarcity rents actually earned by the installed storage technologies in a perfectly competitive energy-only market (orange markers)

Finally, Figure 11 shows the relative change in the system costs with respect to de reference case due to the differences in the capacity mix. The system costs entail all variable costs (fuel costs, emission costs and variable $O \& M$ costs) and the fixed costs (investment costs and fixed O\&M costs) associated with the conventional generators and the storage technologies. The fixed costs associated with the renewable technologies are excluded since they are equal in every situation and are not part of the optimization. As can be seen, the suboptimality is the largest when the $C C^{S V}$-curve is used (around $1.4 \%$ for an E/P-ratio of 2 to $4 \mathrm{Wh} / \mathrm{W}$; and $0.94 \%$ for an E/P-ratio of $6 \mathrm{Wh} / \mathrm{W}$ ). This suboptimality is solely due to the higher investment costs due to the overinvestment in peak generators. Furthermore, the total suboptimality caused by the $C C^{P L R}$-curve is overall lower than the suboptimality caused by the $C C^{S V}$-curve. However, this smaller suboptimality is entirely caused by the decrease in variable costs due to a higher storage penetration, as the fixed costs associated with the changes in the capacity mix are higher than is the case for the $C C^{S V}$-curve. Introducing the penalty term results in a capacity mix that is close to the optimal reference capacity mix and henc, the observed suboptimality is almost equal to zero.

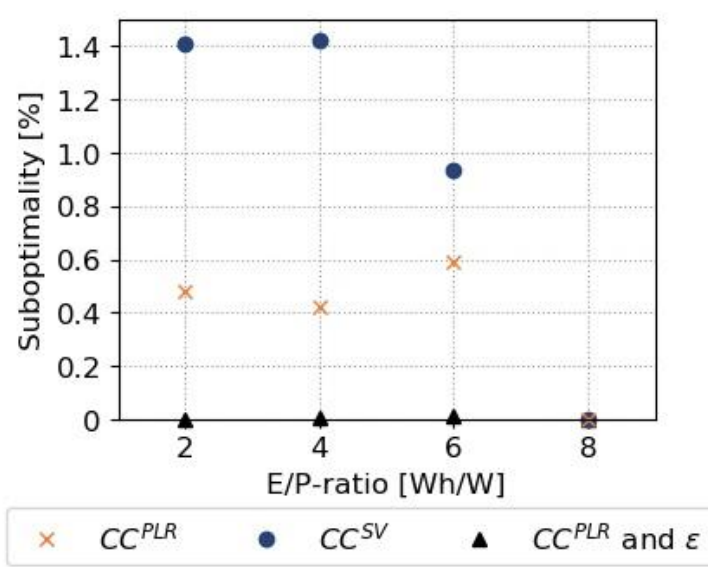

Figure 11: Relative change in system costs due to the suboptimal capacity mix. 


\section{Conclusion}

A capacity credit of any technology may reflect its ability to reduce the peak demand or the value it holds for the system. Regardless of its interpretation, the capacity credit of storage technologies is dependent (i) on the underlying power system, (ii) the storage penetration and (iii) the storage characteristics. Since in planning models and capacity markets the capacity mix is not known a priori, it is difficult to attribute a correct value to the capacity credit storage technologies. As such, to accurately capture the capacity value or contribution to reduce the peak load of storage technologies in planning models/capacity markets, an iterative procedure is required. This ensures that the imposed capacity credit is in line with the resulting capacity mix.

Current methods to estimate the capacity credit of storage technologies are often based on the a technology's ability to reduce the peak residual load which can cause an overestimation of the true capacity value. Likewise, if a value-based capacity credit would be used, this would underestimate the contribution to the capacity target and as such lead to excessive investments in other forms of firm capacity. These biases originate from the fact that a capacity credit used in a capacity constraint fulfills two purposes, namely (i) they determine the share of the installed capacity that can contribute in reaching the imposed target capacity and (ii) they determine the share of the implicit capacity payment that can be earned by the technology at hand. As a result, technology biases and inflated total system costs may appear. The novel method introduced in this paper successfully removes these biases, as it allows simultaneously correctly evaluating the system value of the storage asset, as well as its contribution to reduce the peak load in the context of a long-term planning model with a planning reserve margin-constraint.

Our results can also be interpreted from the perspective of a capacity market. In our case study, using either capacity credit interpretation results in a more expensive capacity mix than a perfectly functioning energy-only market. Furthermore, if peak load reduction-based capacity credits are used, storage technologies see a higher capacity payment than they would earn scarcity rents in a perfectly functioning energy-only market. From this it can be inferred that storage owners might favor the introduction of a capacity mechanism if the capacity credits would not be chosen appropriately.

Finally, it has to be stated that the methodology used was only applied to storage technologies with a fixed amount of iRES, which made it straightforward to derive the CC curves. In reality, also the installed iRES capacity is not known a priori, which makes the derivation of these curves impractical. As such, the iterative procedure needs to be adapted so that the capacity credit of every technology is updated after each iteration. This is subject for future work.

\section{Acknowledgement}

The research of Tim Mertens is supported by a PhD grant provided by the Flemish Institute for Technological Research (VITO). Kenneth Bruninx is a post-doctoral research fellow of the Research Foundation - Flanders (FWO) at the University of Leuven and EnergyVille (mandate no. 12J3320N). 


\section{References}

[1] Balducci, P. J., Alam, M. J. E., Hardy, T. D., \& Wu, D. (2018). Assigning value to energy storage systems at multiple points in an electrical grid. Energy \& Environmental Science, 11(8), 1926-1944.

[2] Loulou, R., Remme, U., Kanudia, A., Lehtila, A., \& Goldstein, G. (2005). Documentation for the times model part ii. Energy Technology Systems Analysis Programme.

[3] Cohen, S. M., Becker, J., Bielen, D. A., Brown, M., Cole, W. J., Eurek, K. P., ... \& Jadun, P. (2019). Regional Energy Deployment System (ReEDS) Model Documentation: Version 2018 (No. NREL/TP-6A20-72023). National Renewable Energy Lab.(NREL), Golden, CO (United States).

[4] Bothwell, C., \& Hobbs, B. F. (2017). Crediting wind and solar renewables in electricity capacity markets: the effects of alternative definitions upon market efficiency. The Energy Journal, 38 (KAPSARC Special Issue).

[5] Milligan, M., Frew, B., Ibanez, E., Kiviluoma, J., Holttinen, H., \& Söder, L. (2017). Capacity value assessments of wind power. Wiley Interdisciplinary Reviews: Energy and Environment, 6(1), e226.

[6] Chen, F., Li, F., Feng, W., Wei, Z., Cui, H., \& Liu, H. (2019). Reliability assessment method of composite power system with wind farms and its application in capacity credit evaluation of wind farms. Electric Power Systems Research, 166, 73-82.

[7] Madaeni, S. H., Sioshansi, R., \& Denholm, P. (2012). Comparison of capacity value methods for photovoltaics in the Western United States (No. NREL/TP-6A20-54704). National Renewable Energy Lab.(NREL), Golden, CO (United States).

[8] Milligan, M., \& Porter, K. (2006). The capacity value of wind in the United States: Methods and implementation. The Electricity Journal, 19(2), 91-99.

[9] Amelin, M. (2009). Comparison of capacity credit calculation methods for conventional power plants and wind power. IEEE Transactions on Power Systems, 24(2), 685-691.

[10] Dragoon, K., \& Dvortsov, V. (2006). Z-method for power system resource adequacy applications. IEEE Transactions on Power Systems, 21(2), 982-988.

[11] Aghaei, J., Akbari, M. A., Roosta, A., \& Baharvandi, A. (2013). Multiobjective generation expansion planning considering power system adequacy. Electric Power Systems Research, 102, 8-19.

[12] Frew, B. A., Cole, W. J., Sun, Y., Mai, T. T., \& Richards, J. (2017). 8760-based method for representing variable generation capacity value in capacity expansion models (No. NREL/CP-6A20-68869). National Renewable Energy Lab.(NREL), Golden, CO (United States).

[13] Zhou, E., Cole, W., \& Frew, B. (2018). Valuing variable renewable energy for peak demand requirements. Energy, 165, 499-511.

[14] Parks, K. (2019). Declining Capacity Credit for Energy Storage and Demand Response With Increased Penetration. IEEE Transactions on Power Systems, 34(6), 4542-4546.

[15] Tuohy, A., \& O'Malley, M. (2009, July). Impact of pumped storage on power systems with increasing wind penetration. In 2009 IEEE Power \& Energy Society General Meeting (pp. 1-8). IEEE.

[16] Madaeni, S. H., Sioshansi, R., \& Denholm, P. (2012). Estimating the capacity value of concentrating solar power plants with thermal energy storage: A case study of the southwestern United States. IEEE Transactions on Power Systems, 28(2), 1205-1215.

[17] Sioshansi, R., Madaeni, S. H., \& Denholm, P. (2013). A dynamic programming approach to estimate the capacity value of energy storage. IEEE Transactions on Power Systems, 29(1), 395-403.

[18] Frazier, A. W., Cole, W., Denholm, P., Greer, D., \& Gagnon, P. (2020). Assessing the potential of battery storage as a peaking capacity resource in the United States. Applied Energy, 275, 115385.

[19] Denholm, P., Nunemaker, J., Gagnon, P., \& Cole, W. (2020). The potential for battery energy storage to provide peaking capacity in the United States. Renewable Energy, 151, 1269-1277. 
[20] National Grid. 2020. Capacity Market Auction Guidelines. Accessed 17 July 2020. https://www.emrdeliverybody.com/Capacity\%20Markets\%20Document\%20Library/Auction\%20Guidelines\%2020 20_T-1_T-3_T-4.pdf

[21] Zachary, S., Wilson, A., \& Dent, C. (2019). The integration of variable generation and storage into electricity capacity markets. arXiv preprint arXiv:1907.05973.

[22] Biggar, D. R., \& Hesamzadeh, M. R. (2014). The economics of electricity markets. John Wiley \& Sons.

[23] European Network of Transmission System Operators for Electricity (ENTSO-E), "ENTSO-E Transparency Platform," 2020.

[24] Projected costs of generating electricity, 2015 edition. Tech. rep. Paris, France: International Energy Agency (IEA), Nuclear Energy Agency (NEA); 2015.

[25] IRENA (2017), Electricity Storage and Renewables: Costs and Markets to 2030, International Renewable Energy Agency, Abu Dhabi.

[26] Pfenninger, Stefan and Staffell, lain (2016). Long-term patterns of European PV output using 30 years of validated hourly reanalysis and satellite data. Energy 114, pp. 1251-1265. doi: 10.1016/j.energy.2016.08.060

[27] Staffell, lain and Pfenninger, Stefan (2016). Using Bias-Corrected Reanalysis to Simulate Current and Future Wind Power Output. Energy 114, pp. 1224-1239. doi: 10.1016/j.energy.2016.08.068

[28] Elia grid data. http://www.elia.be/nl/grid-data/data-download. 


\section{Appendix A: Derivation and interpretation of the first-order optimality conditions}

\section{Introduction to the relevant dual variables and their market interpretation}

A property of dual variables is that they reflect the amount with which the objective value changes when the associated constraint is relaxed infinitesimally. This property is a very useful one and we will apply it to give all dual variables a tangible interpretation in the context of electricity markets.

The dual variable of the power balance constraint (Eq. (2)), i.e., $\lambda_{t}$ corresponds to the cost associated with supplying one additional infinitesimal unit of power demand at time step $t$. As such, $\lambda_{t}$ can be thought of as the power price that would emerge from a perfectly competitive day-ahead market in which all technologies $g$ and $s$ would participate. Given that the objective value (total cost) generally increases as the power demand increases, it can be stated that $\lambda_{t}$ is mostly a positive value and often ${ }^{9}$ corresponds to the marginal cost of the marginal generator. Note that $\lambda_{t}$ is expressed in euros per MW, while it is more practical to work with the electricity (energy) price expressed in Euros per MWh. Therefore, in the remainder of this paper we will work with a related variable $\lambda_{t}^{*}=\frac{\lambda_{t}}{\Delta T}$, which expresses the electricity price per MWh.

Furthermore, the dual variables associated with constraints (5), (6) and (7), i.e., $\alpha_{s, t}, \beta_{s, t}$ and $\gamma_{s, t}$ respectively reflect the operational value associated with having a marginal addition in charging, discharging and energy capacity. Since adding capacity can only result in a decreasing (or unchanged) objective value, these dual variables are always negative (or zero). Very similar to $\mu_{g, t}$ and $v_{g, t}$ which represent the infra-marginal rents of conventional and renewable generators, $\alpha_{s, t}$ and $\beta_{s, t}$ can be interpreted as the economic rent earned per unit of power capacity by charging, respectively discharging at time $t$. Likewise, $\gamma_{s, t}$ can be thought of as the economic rent earned per unit of energy capacity by actually having energy stored in storage unit $s$ at time $t$.

Probably the most challenging variable to interpret is the dual variable of the constraint tracking the energy level over time (Eq . (8)), i.e., $\delta_{s, t}$. To assess the meaning of this dual variable, we rewrite Eq. (8) in function of the change in the energy content of the storage unit.

$$
\Delta e_{s, t \rightarrow t+1}-\sqrt{\eta_{s}} \cdot c h_{s, t} \cdot \Delta T+\frac{d c_{s, t}}{\sqrt{\eta_{s}}} \cdot \Delta T=0
$$

Observe the above equation for a time step at which the storage unit is charges. In such a case, $\delta_{s, t}$ represents the operational cost associated with increasing the energy level of storage unit $s$ at time $t$ by one unit. Since increasing the energy content of a storage unit requires additional charging and hence, additional electricity generation at time $t$, this variable is mostly positive. The same interpretation holds for any discharging time step, i.e., $\delta_{s, t}$ still represents the operational cost associated with increasing the energy level of storage unit $s$ at time $t$ by one unit. However, this time not by charging more at time $t$, but by discharging less at time $t$. Again $\delta_{s, t}$ is positive since discharging less also means increasing electricity generation. From a market perspective $\delta_{s, t}$ reflects the revenue that would be received by selling one unit of stored energy inside storage unit $s$ at a perfectly competitive day-ahead market in which all technologies participate at time $t$. The marginal value of the stored energy should be interpreted as the revenue obtained in the future for energy stored now.

\section{Summary}

Table 5 summarizes the relevant dual variables and their different interpretations.

\begin{tabular}{|c|c|c|c|c|}
\hline $\begin{array}{c}\text { Dual } \\
\text { variable }\end{array}$ & Dual variable property & Market interpretation & Unit & Sign \\
\hline$\lambda_{t}^{*}=\frac{\lambda_{t}}{\Delta T}$ & $\begin{array}{l}\text { Cost associated with supplying } \\
\text { a marginal additional unit of } \\
\text { demand at time } t \text {. }\end{array}$ & $\begin{array}{l}\text { Electricity price that would } \\
\text { emerge from a perfectly } \\
\text { competitive day-ahead } \\
\text { market in which all } \\
\text { technologies would } \\
\text { participate at time } t \text {. }\end{array}$ & $€ / \mathrm{MWh}$ & $\begin{array}{l}\text { Mostly } \\
\text { positive }\end{array}$ \\
\hline$\alpha_{s, t}$ & $\begin{array}{l}\text { Cost decrease brought about } \\
\text { by having an additional unit of } \\
\text { charging capacity of technology } \\
s \text { at time step } t \text {. }\end{array}$ & $\begin{array}{l}-\alpha_{s, t}: \text { Economic rent earned } \\
\text { per unit of power capacity by } \\
\text { storage unit } s, \text { while charging } \\
\text { at time step } t \text {. }\end{array}$ & $€ / \mathrm{MW}$ & Negative \\
\hline$\beta_{s, t}$ & $\begin{array}{l}\text { Cost decrease brought about } \\
\text { by having an additional unit of }\end{array}$ & $\begin{array}{l}-\boldsymbol{\beta}_{s, t}: \text { Economic rent earned } \\
\text { per unit of power capacity by }\end{array}$ & $€ / \mathrm{MW}$ & Negative \\
\hline
\end{tabular}

${ }^{9}$ Later it will be shown that the presence of storage technologies this dual variable can deviate from marginal costs of generators. 


\begin{tabular}{|c|c|c|c|c|}
\hline & $\begin{array}{ll}\text { discharging capacity of } \\
\text { technology } s \text { at time step } t .\end{array}$ & $\begin{array}{l}\text { storage unit } s, \quad \text { while } \\
\text { discharging at time step } t \text {. }\end{array}$ & & \\
\hline$\gamma_{s, t}$ & $\begin{array}{l}\text { Cost decrease brought about } \\
\text { by having an additional unit of } \\
\text { energy capacity of technology } s \\
\text { at time step } t \text {. }\end{array}$ & $\begin{array}{l}-\gamma_{s, t}: \text { Economic rent earned } \\
\text { per unit of energy capacity by } \\
\text { having energy stored in } \\
\text { storage unit } s \text { at time } t \text {. }\end{array}$ & $€ / M W h$ & Negative \\
\hline$\delta_{s, t}$ & $\begin{array}{l}\text { Cost increase associated with } \\
\text { increasing the energy level of } \\
\text { storage unit } s \text { at time } t \text { by one } \\
\text { unit (through charging more or } \\
\text { discharging less). }\end{array}$ & $\begin{array}{l}\text { Marginal value of having } \\
\text { energy stored inside storage } \\
\text { unit } s \text { at time } t \text {. }\end{array}$ & $€ / M W h$ & $\begin{array}{l}\text { Mostly } \\
\text { positive }\end{array}$ \\
\hline
\end{tabular}

Table 5: Overview of the relevant dual variables and their interpretations

\section{First-order optimality conditions for integral storage technologies}

\section{Charge condition}

Eq. (20) reflects the first-order optimality conditions associated with the charge variables.

$$
\frac{\partial L}{\partial c h_{s, t}}=\lambda_{t}-\alpha_{s, t}-\sqrt{\eta_{s}} \cdot \Delta T \cdot \delta_{s, t}=0
$$

As such, the dual variable of constraint (5) can be written in function of $\delta_{s, t}$ and $\lambda_{t}$.

$$
-\alpha_{s, t}=\sqrt{\eta_{s}} \cdot \delta_{s, t} \cdot \Delta T-\lambda_{t}=\left(\sqrt{\eta_{s}} \cdot \delta_{s, t}-\lambda_{t}^{*}\right) \cdot \Delta T
$$

Following the market interpretation of the dual variables, Equation (21) expresses that the economic rent earned while charging is equal to the difference between (i) the marginal value of charging electricity at time $t$ and (ii) the marginal cost of charging at time $t$, i.e., the electricity price. Note that the marginal value of charging is equal to the value of the stored energy times the charging efficiency because charging $1 \mathrm{MWh} / \mathrm{h}$ increases the storage level by only $\sqrt{\eta_{s}} \mathrm{MWh} / \mathrm{h}$.

The leftmost dispatch situation depicted in Figure 12 illustrates the meaning of Eq. (21). As can be seen, the mid-merit technology mostly sets the electricity price (dashed line) throughout the day. As such, the marginal value of the stored energy $\left(\delta_{t}\right.$, light blue line) is constant and equal to $\sqrt{\eta_{s}}$ times the marginal cost of the mid-merit technology. The value of the stored energy should be interpreted as the marginal revenue received eventually for discharging the stored energy. Since discharging one $M W h / h$ requires the storage level to decrease by $\frac{1}{\sqrt{\eta_{s}}} M W h / h$ the marginal value of the stored energy is equal to the mid-merit marginal cost times the discharge efficiency. As can be seen from the dispatch situation, around midday there is an abundance renewable generation which temporarily pushes the electricity price down to the marginal cost of the base technology. As such, during three consecutive hours the marginal cost of charging is lower than the marginal value of charging and hence, according to Equation (21), charge rents are earned during these hours (dark grey line).

Note that charge rents are earned when the charge capacity is insufficient to fully exploit a temporary drop in the electricity price. In the first dispatch situation of Figure 12 the charge capacity is insufficient to charge more electricity generated by the base technology. If the charge capacity would be higher, charging would continue until the base technology generated at full capacity so that the value of charging becomes equal to the cost of charging and the charging rent disappears.

\section{Discharge condition}

Very similar to Eq. (20), Eq. (22) expresses the first-order optimality conditions associated with the discharge variables.

$$
\frac{\partial L}{\partial d c_{s, t}}=-\lambda_{t}-\beta_{s, t}+\frac{\delta_{s, t}}{\sqrt{\eta_{s}}} \cdot \Delta T=0
$$

The dual variable of constraint (6) can be written in function of $\delta_{s, t}$ and $\lambda_{t}$.

$$
-\beta_{s, t}=\left(\lambda_{t}^{*}-\frac{1}{\sqrt{\eta_{s}}} \cdot \delta_{s, t}\right) \cdot \Delta T
$$


Eq. (23) implies that the economic rent earned while discharging is equal to the difference between (i) the marginal value obtained by discharging at time $t$, i.e., the electricity price, and (ii) the marginal cost of discharging ${ }^{10}$. Note that the marginal cost of discharging is equal to the value of the stored energy divided by the discharging efficiency since discharging $1 \mathrm{MWh} / \mathrm{h}$ requires the storage level to decrease by $\frac{1}{\sqrt{\eta_{s}}} \mathrm{MWh} / \mathrm{h}$.

The middle dispatch situation depicted in Figure 12 illustrates a day in which a discharge rent is earned. Again, the mid-merit technology sets the electricity price for most hours. However, the value of the stored energy $\left(\delta_{t}\right.$, light blue line) is equal to $\frac{1}{\sqrt{\eta_{s}}}$ times the mid-merit marginal cost. The reason why this value is higher than the marginal cost of the mid-merit technology is that the storage unit prevents the deployment of the peak generator and acts as the marginal generator. The value of the stored energy should be interpreted here as the price of preventing the deployment of the peak generator during the discharge hours. ${ }^{11}$ As can be seen, during the 8 th hour of the day the discharge capacity is reached which causes the peak generator to set the electricity price. According to Eq. (23), a discharge rent is earned since the marginal value of discharging exceeds the marginal cost of discharging.

Note that discharge rents are earned whenever the discharge capacity is insufficient to prevent the temporary usage of a more expensive generation technology. In the middle dispatch situation of Figure 12, due to the limited discharge capacity the storage unit cannot prevent the peak generator from becoming the marginal generator, causing the price to spike. If the discharge capacity was larger, discharging would continue up to the point that the mid-merit technology becomes the marginal generator again, which would make the discharge rent disappear.

\section{Energy level condition}

Eqs. (24) and (25) express the first-order optimality conditions associated with the constraint (8) which tracks the energy level of the storage units.

$$
\begin{gathered}
\frac{\partial L}{\partial e_{s, t}}=-\gamma_{s, t}+\delta_{s, t}-\delta_{s, t+1}=0 \\
-\gamma_{s, t}=\delta_{s, t+1}-\delta_{s, t}
\end{gathered}
$$

Eq. (25) implies that an economic rent per unit of energy capacity emerges at time $t$ if the marginal value of the stored energy at time $t+1$ exceeds the marginal value of the stored energy at time $t$. These volume rents are earned when the storage unit arbitrages energy between different price regimes. The expression illustrates that there is an economic incentive to transfer energy from $t$ to $t+1$.

The rightmost dispatch situation from Figure 1 illustrates the meaning of equation (15). At hour 16 the value of the stored energy suddenly increases, i.e., there is a jump in the light blue line and hence, a volume rent is earned at this moment. This volume rent emerges whenever energy is arbitraged between a low price period and a high price period in which the is fully charged in the lower price period and fully discharged at the high priced period.

Note that volume rents are earned whenever the energy capacity limits the amount of energy that can be arbitraged. If the energy capacity would be sufficiently large, energy arbitrage between the two price regimes would continue until the difference in price would be leveled out.

${ }^{10}$ Another way of interpreting the marginal cost of discharging is to think about it as a shadow price that is equal to the value of keeping the energy stored inside the storage unit.

${ }^{11}$ Following the dual variable property, the electricity price reflects the marginal cost of supplying an additional unit of demand and as can be seen, this cost is equal to $\frac{1}{\eta_{s}}$ times the mid-merit marginal cost during discharge hours. The interpretation is that in order to facilitate one additional MW of electricity, it is cheaper to charge $\frac{1}{\eta_{s}} \mathrm{MW}$ more (when the mid-merit technology sets the price) than to call upon the peak generator. 

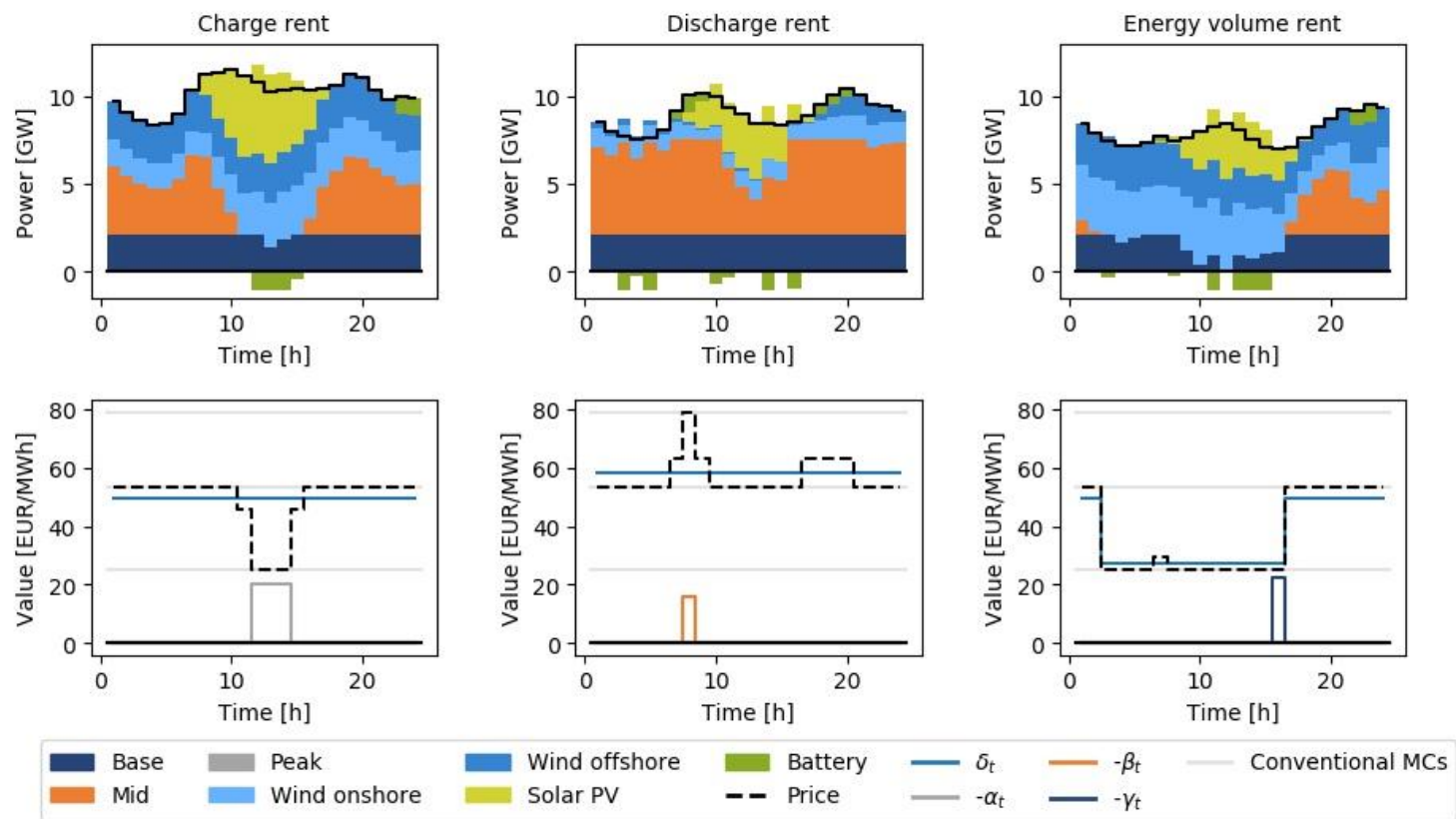

Figure 12: Illustration of the three economic rents that a storage unit can earn. From left to right (i) charge rent, (ii) discharge rent and (iii) energy volume rent.

\section{Energy capacity condition}

Deriving the first-order optimality condition associated with the energy capacity of a storage unit $s$ gives ${ }^{12}$ :

$$
\frac{\partial L}{\partial c a p_{s}^{E}}=F C_{s}^{E}+\frac{F C_{s}^{c h}}{E P_{s}}+\frac{1}{E P_{s}} \cdot \sum_{t \in T} \alpha_{s, t}+\frac{1}{E P_{S}} \cdot \sum_{t \in T} \beta_{s, t}+\sum_{t \in T} \gamma_{s, t}=0
$$

By rearranging terms we end up with an equation that connects the fixed unit cost of the storage technology with the economic rents.

$$
F C_{s}^{E}+\frac{F C_{s}^{P}}{E P_{s}}=-\sum_{t \in T}\left[\gamma_{s, t}+\frac{\alpha_{s, t}+\beta_{s, t}}{E P_{s}}\right]
$$

Eq. (27) expresses that in an optimal solution, the cost per unit of energy capacity must equal the total economic rents earned per unit of energy capacity. Note that all terms in Eq. (17) are expressed per unit of energy capacity. To obtain the same expression per unit of installed power capacity, we only need to multiply both sides by the energy-to-power ratio.

$$
F C_{s}^{E} \cdot E P_{s}+F C_{s}^{P}=-\sum_{t \in T}\left[\gamma_{s, t} \cdot E P_{s}+\alpha_{s, t}+\beta_{s, t}\right]
$$

12 For disjoint technologies we would obtain three distinct first-order optimality conditions, one for each investment variable. 


\section{On the authors:}

Tim Mertens (tim.mertens@kuleuven.be) received the M.Sc. degree in energy engineering in 2016 from the Univeristy of Leuven (KU Leuven), Belgium. Currently, he is a PhD candidate in the Energy Systems Integration and Modeling Group at the University of Leuven and EnergyVille. The research of Tim Mertens is supported by a PhD grant provided by the Flemish Institute for Technological Research (VITO).

Kenneth Bruninx (kenneth.bruninx@kuleuven.be) received the M.Sc. degree in energy engineering in 2011 and the Ph.D. degree in mechanical engineering in 2016, both from the Univeristy of Leuven (KU Leuven), Belgium. Currently, he is working as a post-doctoral research fellow of the Research Foundation - Flanders (FWO) (grant no. 12J3320N) in the Energy Systems Integration and Modeling Group at the University of Leuven and EnergyVille.

Erik Delarue (erik.delarue@kuleuven.be) received the M.Sc. degree in mechanical engineering in 2005 and the Ph.D. degree in mechanical engineering in 2009, both from the University of Leuven (KU Leuven), Belgium. Currently, he is Assistant Professor at the University of Leuven, leading the Energy Systems Integration and Modeling Group, and active in EnergyVille.

\section{On the research group:}

The Energy Systems Integration \& Modeling Group is part of the division of Applied Mechanics and Energy Conversion (TME) of the Department of Mechanical Engineering of KU Leuven in Belgium. E. Delarue and W. D'haeseleer lead this research group, currently about $15 \mathrm{PhD}$ students and post-doctoral research fellows, dedicated to the modeling of integrated energy systems and markets. This young research group has already gained significant expertise and international recognition in the field. A major strength of this group is its interdisciplinary focus (techno-economic models, link to energy policies and markets). The group is further strongly embedded in EnergyVille, an association of the Flemish research institutes KU Leuven, VITO, imec and UHasselt in the field of sustainable energy and intelligent energy systems. EnergyVille brings research, development, training and industrial innovation together under one name, in close cooperation with local, regional and international partners. 